\section{Cool philosophies}

\section{High-energy physicists should not gloss over fundamental conundrums.}

W hether through calculated seduction or natural attraction, the Large Hadron Collider (LHC), which starts up next week, seems to be enjoying a love affair with the media and the public. Some may revel in the Herculean feat of engineering at CERN, the particle-physics laboratory near Geneva, that has created a 27-kilometre tunnel colder than the outer cosmos. But the LHC's most potent allure surely stems from the air of mystery that attaches to its promise to reveal secrets from the first milliseconds of the Big Bang - in lay terms, to explain how it all began.

Needless to say, the LHC cannot do quite that. But it should tell us something about the origins of mass, courtesy of the much-vaunted Higgs boson, as well as casting light on the asymmetry between matter and antimatter, and the nature of the quark-gluon plasma that seethed before the Universe was cool enough to make nuclear particles. We might even catch glimpses of the truly exotic: spawnings of tiny black holes and their evaporation, and signs of extra dimensions. The excitement and anticipation are warranted.

All this places a fearsome burden of explanation on the physicists involved. Can they convey anything beyond the sound bites above and, if so, how? As Alexei Grinbaum, a physicist and ethicist at CEA-Saclay in Gif-sur-Yvette, France, writes in a stimulating preprint (www.arxiv.org/abs/0806.4268): "The LHC is an opportunity to renew the enthusiasm for understanding the world ... Whether such a change will occur depends ... on how physicists will speak about the LHC and what they will say." He expresses a hope that the discourse will not amount to ex cathedra pronouncements of the sort: "I can't explain without the full mathematics what is really going on."

But as Grinbaum argues, this is not simply a matter of finding the right, non-alienating tone. When physicists, struggling to put across a difficult concept to a lay audience, say (or more probably just think): "Oh, if only I could show you the equations, you would understand," this is not what they really mean. Rather, they mean: "You would understand at the same level as I understand." That is, at the level of mathematical formalism. This is not to imply that physicists hide blindly behind the maths (although some probably do), but that they might not acknowledge or even recognize that the mathematics shields them from genuine conceptual questions.

There is a tendency to wave these questions away as semantic or philosophical, as though such issues by definition cannot be serious. The founders of quantum theory knew otherwise, although some of their dilemmas have still not been resolved. As the philosopher Moritz Schlick said: "It is the mark of the greatest scientific minds that they think out every question they take up right to the end, and the end of every question lies in philosophy." Grinbaum puts it another way: "The job of [the] theoretical physicist is not to write equations."

For the LHC, some of these foundational issues are raised by the role of aesthetics as a guide to physical theory, in particular arguments based on symmetry. At the pragmatic level, symmetry has been an immensely fertile tool, and it underpins the notion of a Higgs mechanism for mass. But there is no rigorous justification for relying on it, and it is possible that the LHC might point the way to a new physics that discards it as a ruling principle.

These questions, which impose themselves only when a complacent reliance on 'the equations' is renounced, could captivate a wide audience as readily as tantalizing references to the first instants of creation. It would be a shame if the teams at the LHC shy away from them.

\section{The hour of diplomacy}

\section{Scientific collaboration between East and West must survive the crisis in Georgia.}

\footnotetext{
L
}

ess than three months ago, hundreds of scientists from Russia, Europe, Asia and North America gathered in Tbilisi, Georgia, for the 2008 Phage Biology, Ecology and Therapy Meeting at the George Eliava Institute of Bacteriophage, Microbiology and Virology. In the light of recent events, it seems unlikely that a similarly illustrious scientific meeting will happen again there any time soon.

But the political reverberations that have inevitably followed the conflict in the Caucasus region should not be allowed to damage science. Indeed, the rougher the language between Moscow and the West, the more valuable it becomes to sustain good relations in research.

Science cannot and should not be blind to politics. But even if the current political crisis escalates, it would be utterly unwise of either side to halt or suspend existing scientific agreements and collaborations. Over the past two decades, East-West scientific relationships have developed from pure unilateral aid to increasingly fruitful collaborations.

This process must continue. Joint efforts in arms control, nuclear non-proliferation and biosafety have made this planet a safer place to live than it was at the height of the cold war. Mechanisms such as the International Science and Technology Center, which since 1992 has provided former weapons scientists with opportunities in international partnerships, have helped prevent Soviet research centres and armouries from becoming shopping paradises for terrorists and dodgy heads-of-state. And the influx to Western labs of countless highly skilled Russian mathematicians, computer scientists and others has propelled advances in fields ranging from bioinformatics to climate modelling.

Looking forward, collaboration with Russia in space, energy and arms limitation will be a key issue for the incoming US administration, and the European Union's member states need to decide whether Russia can join the seventh Framework programme (see page 6).

The current political tensions could all too easily block these avenues of collaboration, which would harm not only Western interests but those of Russia's researchers too. Scientists and political leaders should do everything they can to avoid those outcomes. As Russia regains its strength and pride, direct financial support for Russian science from foreign governments will inevitably decline. What should follow is an equal scientific partnership based on mutual trust, respect and responsibility. Prudent scientific diplomacy is a peace-keeping measure in its own right. 